\title{
An Investigation into Strength and Permittivity of Compacted Sand-Clay Mixtures by Partial Replacement of Water with Lignosulfonate
}

\author{
A. Sezer ${ }^{a, *}$, A. MARdAni-AghaBAglou ${ }^{b}$, A. Boz $^{a}$ And N. TANRINIAN ${ }^{a}$ \\ ${ }^{a}$ Ege University, Department of Civil Engineering, Izmir, Turkey \\ ${ }^{b}$ Uludag University, Department of Civil Engineering, Bursa, Turkey
}

\begin{abstract}
Strength and permeability of sand-bentonite mixtures are of main concern, particularly in liner design. This study presents the results obtained from an experimental investigation of strength and permittivity of compacted sand-bentonite mixtures in the presence of water-reducing admixture of lignosulfonate. For this, sand-bentonite mixtures containing 4, 8, 12, $16 \%$ of bentonite were subjected to standard Proctor tests, to obtain the optimum water content and maximum void ratio of the mixtures. Similar specimens were prepared by partially replacing $0.5,1$ and $2 \%$ of water in the mixture with lignosulfonate. Additional specimens containing $16 \%$ of bentonite were prepared with $5 \%$ deviation towards the wet and dry sides of optimum water content, which was partially replaced with lignosulfonate for evaluation of the effects of deviation from optimum moisture content during densification. It was observed that partial replacement of water with lignosulfonate slightly increases the strength and decreases the permittivity, and that this effect was more pronounced as the replacement level was increased. Additionally, test results reveal that lignosulfonate replacement was more effective on the dry side of optimum water content.
\end{abstract}

DOI: 10.12693/APhysPolA.130.23

PACS/topics: 81.05.Rm, 83.80.Fg, 89.60.-k

\section{Introduction}

In the last century, the need for housing due to population growth has caused a significant reduction in zones available for building construction. Therefore, construction in formerly infeasible zones became possible due to advances in soil improvement techniques. Since plasticity and water content strongly affect the strength of finegrained soils, clay is not generally preferred as a construction material due to its high compressibility, high water content, low permeability and low ultimate bearing capacity. On the other hand, low permeability of clay makes it possible to use it as a liner material. Engineering properties of clays can be improved by desiccation and application of mechanical energy. In the case when these methods are incapable of providing the desired parameters, before considering the deep foundation alternative, use of chemical additives for stabilization is another option. Chemical stabilizers including cement, lime, gypsum and class $\mathrm{C}$ fly ash, change the chemical structure of the fine-grained soils, provide improvement in mechanical properties of clays by void-filling effect and cause a denser and stronger medium by formation of hydration products. Recent studies show that the use of chemical additives improves engineering properties of soils including the increase in bearing capacity, reduction in shrinkage and swell, coupled with a considerable reduction in permeability $[1,2]$. Unfortunately, these alkaline additives change the $\mathrm{pH}$ level of the soil which further hinders vegetation and causes reduction in ground water quality [3].

\footnotetext{
*corresponding author; e-mail: alper.sezer@ege.edu.tr
}

However, it is a well-known fact that conventional additives increase the stiffness of the foundation soils and in the case when the stresses transferred from structural foundations reach the bearing capacity of the foundation soils, the stiffness poses a risk for superstructure $[4,5]$.

On the other hand, lignosulfonate, which is an environmentally friendly by-product of paper and timber industry, is also used in stabilization of soils $[6,7]$. In addition to its utilisation as a concrete and drilling mud additive, lignosulfonate can be used to improve the engineering properties of the soils during the densification [8]. In essence, lignosulfonate is a polymer compound obtained from the wood extract and it consists of hydrophilic and hydrophobic components. Presence of lignosulfonate in soil does not cause environmental problems: it is known as a non-corrosive and a nontoxic chemical material. Nevertheless, the most outstanding feature of this additive is that presence of lignosulfonate in the soil leads to an increase in strength without changing the $\mathrm{pH}$ value of the ground, while soil still remains ductile $[5,9]$. Adams [8] has investigated the environmental effects of lignosulfonate. He has emphasized that acetic acid, which has detrimental effects to environment, is evaporated during the production of lignosulfonate. The study also investigated the environmental effects of increasing lignosulfonate content and no detrimental effects on ground water were observed up to a content of $10 \mathrm{~kg} / \mathrm{m}^{2}$. It should be underlined that this value is larger than the common inclusion level of lignosulfonate $\left(1 \mathrm{~kg} / \mathrm{m}^{2}\right)$. In this way, several studies emphasize a certain increase in strength properties of soils containing lignosulfonate. Variations in physical properties and strength of silty clays improved by 
using stabilizer prepared with liquid sulphuric acid and lignosulfonate have been investigated by Puppala and Hanchanloet [10]. While liquid sulphuric acid tends to increase the soil strength due to pozzolanic reactions, lignosulfonate causes a reduction in the brittleness of soil. Tingle and Santori [6] have investigated the variations in strength of high and low plasticity clays stabilized using twelve different additives including lignosulfonate, cement and lime. Compared with other additives, lignosulfonate leads to a significant increase in strength of clays and it was stated that lignosulfonate was more effective in clays of low plasticity.

Apart from its advantages as a binder material, use of lignosulfonate is economically more feasible, in comparison with cement and lime. Vegetation cannot occur above cement-stabilized soil due to the increase of $\mathrm{pH}$ level. It was underlined that lignosulfonate is free of corrosive and toxic substances [11]. Use of lignosulfonate stabilizes the $\mathrm{pH}$ level and the vegetation remains possible $[12,13]$. Evaluation of compressive strength of stabilized specimens has shown that similar strength values could be obtained using lower amounts of lignosulfonate, in comparison with traditional stabilizers [6, 12]. Several studies include microstructural analyses for a better evaluation of interaction between grains and lignosulfonate $[8,13]$. X-ray diffraction analysis results have revealed that crystallization or irregular compounds were not observed in dispersive clays stabilized by lignosulfonate. Decrease in size of crystalline structure depends on the electrostatic reaction between clay minerals and lignosulfonate. Electrostatic reaction decreases the negative charge of clay minerals and promotes bonding between them.

All these studies emphasize that stabilization of soil by lignosulfonate leads to improvement in mechanical properties of soils. As is widely known, fat clay-sand mixtures are used as liner materials. High strength, low permeability, limited volumetric change after interaction with water are several properties expected from these materials. In this scope, we present an investigation into evaluation of unconfined compressive strength and chloride-ion penetration of fat clay treated and densified by use of a lignosulfonate-based water reducing admixture. The results are evaluated in detail.

\section{Experimental study \\ 2.1. Materials}

Before the preparation of specimens, physical and chemical properties of bentonite were evaluated. The Atterberg limits were determined in accordance with ASTM D4318 standard. Liquid limit, plastic limit and plasticity index were determined as $191 \%, 76 \%$ and $114 \%$, respectively. Chemical properties of bentonite, provided by the manufacturer are given in Table I.

Uniform quartz sand of particle size between 0.8 and $1.1 \mathrm{~mm}$ was used in preparation of mixtures. Lignosulfonate-based water reducing admixture (LSA) was used for partial replacement of water in the mixture. The properties of LSA are given in Table II.
TABLE I

Chemical properties of bentonite.

\begin{tabular}{c|c}
\hline \hline Component & Content [\%] \\
\hline $\mathrm{SiO}_{2}$ & 73.00 \\
$\mathrm{Al}_{2} \mathrm{O}_{3}$ & 13.00 \\
$\mathrm{Fe}_{2} \mathrm{O}_{3}$ & 0.70 \\
$\mathrm{CaO}$ & 1.10 \\
$\mathrm{MgO}$ & 3.00 \\
$\mathrm{TiO}_{2}$ & 0.05 \\
$\mathrm{Na}_{2} \mathrm{O}$ & 0.25 \\
$\mathrm{~K}_{2} \mathrm{O}$ & 1.10 \\
L.O.I. & 6.50
\end{tabular}

TABLE II

Several properties of high-range lignosulfonate-based water reducing admixture.

\begin{tabular}{c|c|c|c|c}
\hline \hline $\begin{array}{c}\text { Alkali } \\
\text { content } \\
{[\%]\left(\mathrm{Na}_{2} \mathrm{O}\right)}\end{array}$ & $\begin{array}{c}\text { Density } \\
{\left[\mathrm{g} / \mathrm{cm}^{3}\right]}\end{array}$ & $\begin{array}{c}\text { Solids } \\
\text { content } \\
{[\%]}\end{array}$ & $\begin{array}{c}\text { Chloride } \\
\text { content } \\
{[\%]}\end{array}$ & $\begin{array}{c}\mathrm{pH}, \\
25^{\circ} \mathrm{C}\end{array}$ \\
\hline$<5$ & 1.24 & 47 & 0.33 & 6.87
\end{tabular}

\subsection{Preparation of specimens and testing procedure}

Regarding the properties of the materials given above, an experimental framework was set up to evaluate the effects of lignosulfonate on sand-bentonite mixtures. For this reason, in addition to the mixture free of bentonite and LSA, 12 mixtures were prepared by replacement of sand $(4,8,12$ and 16\%) with bentonite and by substitution of water $(0,1$ and $2 \%$ ) with LSA. In addition, for mixtures containing $16 \%$ bentonite, at 0, 0.5, 1 and $2 \%$ of LSA, two additional specimens (for each mixture) with $5 \%$ deviation towards the dry and wet side of optimum condition were prepared and subjected to strength and permittivity testing. A total of 28 mixtures were prepared and tested. During the preparation of the specimens, bentonite was initially mixed with sand at varying contents of 4, 8, 12 and $16 \%$, by weight. Later, standard Proctor tests were conducted to find out the maximum dry unit weight and corresponding optimum water content of the mixtures. The optimum moisture content of

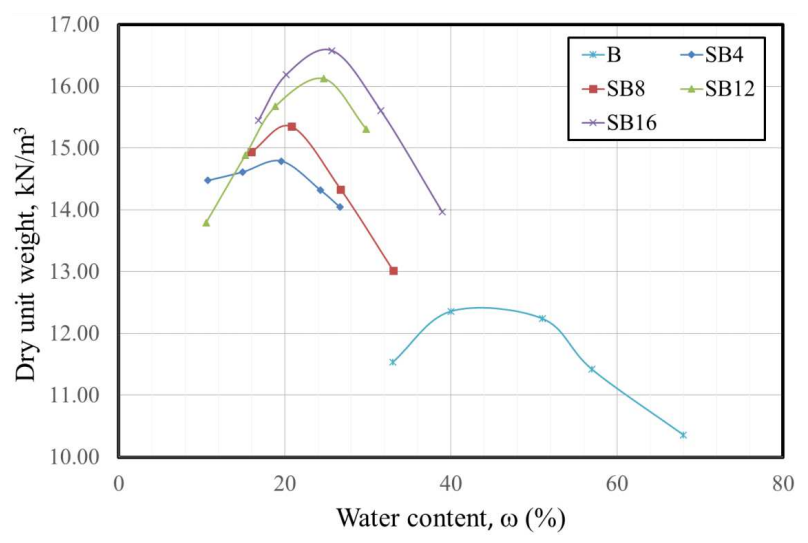

Fig. 1. Compaction curves of mixtures. 
each mixture was obtained in accordance with the ASTM D698 standard. The outcomes of the compaction tests, Proctor curves are given in Fig. 1.

In Fig. 1, B and S indicate bentonite and sand, respectively. The specimens were designated by the replacement level of bentonite and LSA. For example, if the mixture contains $16 \%$ bentonite and $2 \%$ of LSA, it is designated as SB16-LS2. From the analysis of Fig. 1, it is clear that inclusion of bentonite leads to a significant increase in dry unit weight of the specimens, and this increase is more evident with the increasing bentonite content. Needless to say, optimum moisture content of bentonite itself is $45 \%$, and this value is higher, in comparison with that of the specimens containing sand. The results of Proctor tests also have revealed that bentonite content does not remarkably influence the optimum moisture content of the sand/bentonite mixtures. The optimum moisture content of these mixtures has ranged between 19.5 and $24 \%$.

The diameter and length of unconfined compressive test specimens were 50 and $100 \mathrm{~mm}$, respectively. The specimens were prepared at their optimum moisture content determined from standard Proctor tests. Specially designed cylindrical split molds, having diameter and length of 100 and $50 \mathrm{~mm}$ were used to prepare chloride-ion penetration test specimens. The specimens were identical with unconfined compressive test specimens. Standard Proctor effort and the optimum moisture content were used to prepare the chloride ion penetration test specimens.

The unconfined compression strength and chloride-ion penetration of specimens were determined in accordance with ASTM D2166 and ASTM C1202 standards, respectively. In order to determine the chloride-ion penetration of specimens, the amount of electrical current flowing through the specimen was measured for 1 hour. At the end of 1 hour, the total charge passed through the sample, which is a measure of the resistance to chloride ion penetration, was determined.

\section{Results and discussion}

\subsection{Unconfined compressive strength}

Unconfined compressive strength tests were carried out to investigate the benefits of LSA in terms of strength property. The stress-strain plots obtained from tests carried out on specimens containing $0 \%$ and $2 \%$ of LSA are given in Figs. 2 and 3, respectively. Results of unconfined compressive strength values are summarized in Fig. 4. As can be seen from Fig. 2, unconfined compressive strength of specimens increases with the increasing sand content. This is expected, since inclusion of sand should cause an increase in strength due to increase in dry unit weight. From Figs. 2, 3 and 4, it may be observed that partial replacement of water by LSA causes an increases in unconfined compressive strength of specimens and this increase is more evident with the increase of the LSA content. This behaviour may be attributed to reduction in optimum water content of the mixture by the increase

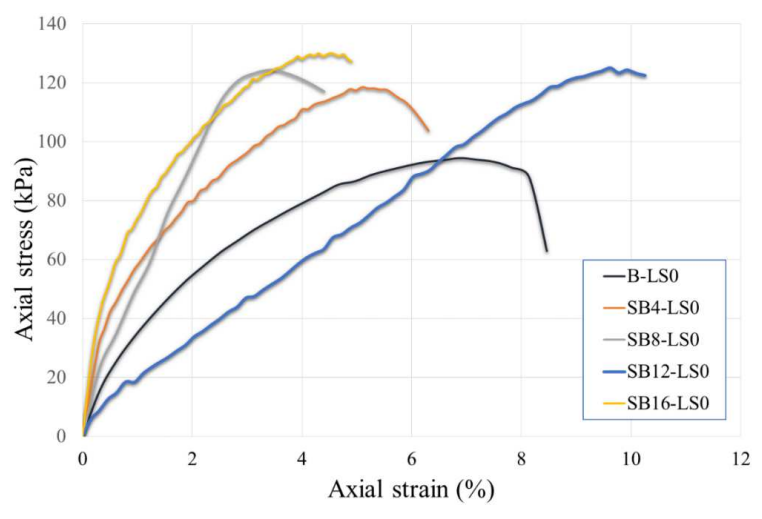

Fig. 2. Unconfined compressive strength test results for specimens without LSA.

of LSA content. As known, water requirement of the mixture decreases with addition of LSA. As expected, the BS16-dry and BS16-wet samples show better and worse strength performance, respectively, compared to the BS16 sample, which may be attributed to decreased water demand and subsequent desiccation provided by partial replacement of water by the LSA.

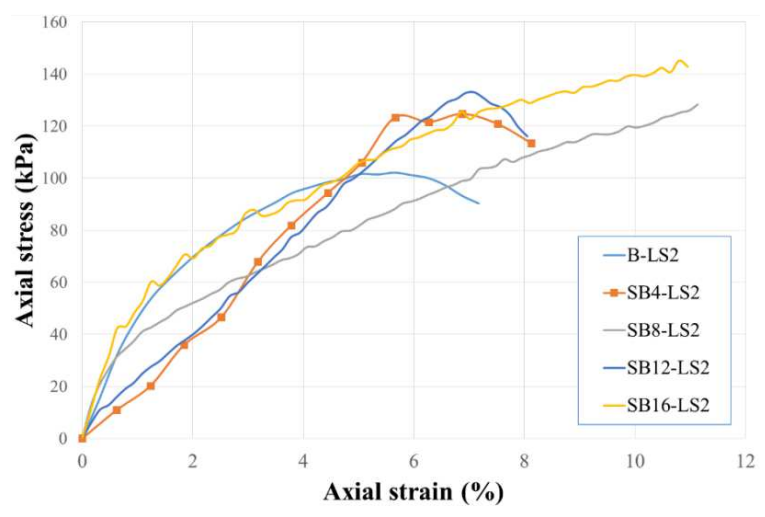

Fig. 3. Unconfined compressive strength test results for specimens containing $2 \%$ of LSA.

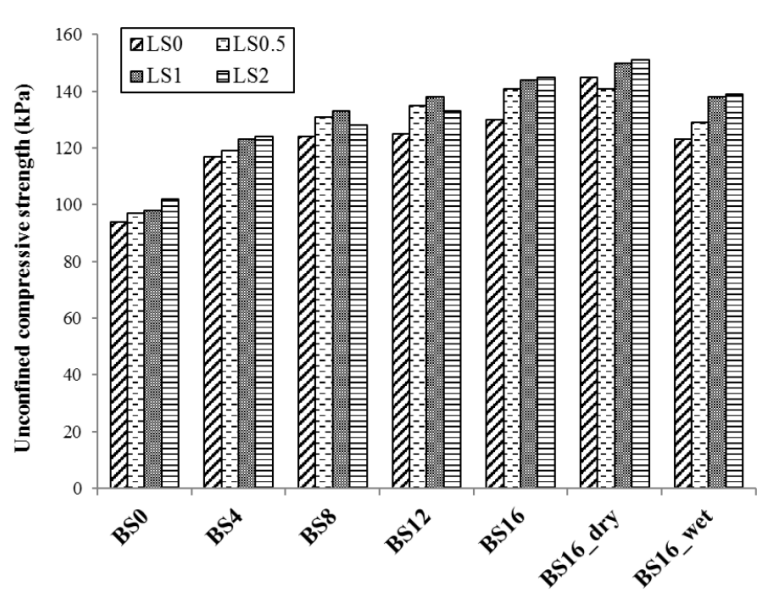

Fig. 4. Variation in unconfined compressive strength of specimens containing LSA. 
Specimens containing LSA showed a more ductile behavior, in comparison with those free of lignosulfonate. The increase in unconfined compressive strength with partial replacement of water by LSA was generally of the order of 5 to $10 \%$. From the analysis of the strength behavior, $1 \%$ of LSA substitution seems to be an optimal value. The increase in LSA substitution level from 1 to $2 \%$ does not cause a significant increase in unconfined compressive strength of the specimens. LSA substitution has positively affected the strength of all specimens, however, the increase in strength was limited.

\subsection{Chloride-ion penetration}

Results of chloride-ion penetration test of the samples are shown in Figs. 5 and 6 . As can be observed from the test results, chloride-ion penetration of samples decreases with the increasing sand content and LSA substitution level. The total porosity of specimens was reduced by increasing the amount of sand. Bentonite has a role of filler in the system. As known, the viscosity of mixture may be increased by using the water-reducing admixture. Application of the same compaction energy leads to lower void ratios since a denser structure forms by inclusion of materials of different particle sizes. Increase in unit weight of samples with increasing amount of bentonite and water-reducing admixture content can be considered a proof of this result. Similar to the results obtained from strength tests, as it was expected, BS16-dry and BS16wet samples show better and worse transport properties compared to the BS16 sample, respectively.

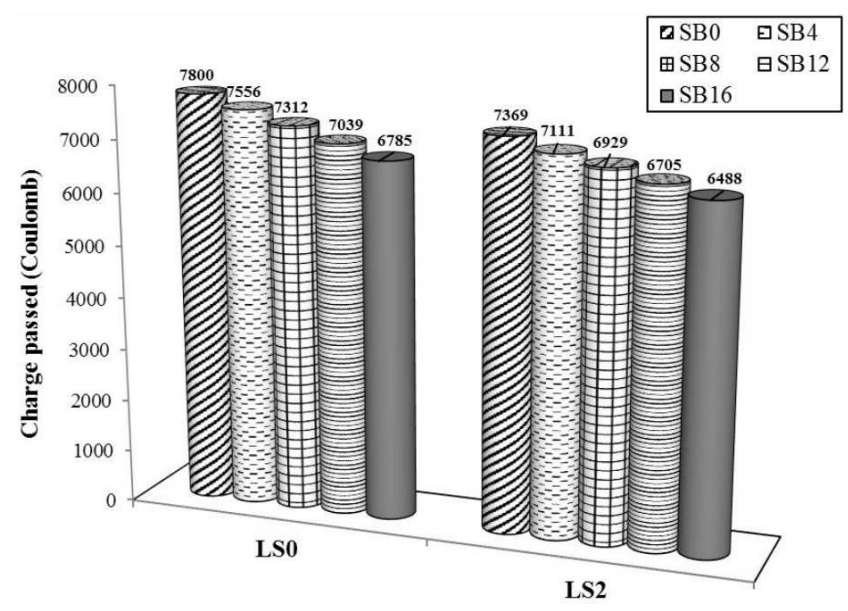

Fig. 5. Variation of chloride-ion penetration of specimens by substitution of 0 and $2 \%$ of water by LSA.

Additionally, the relationship between unconfined compressive strength and chloride-ion penetration of the samples is shown in Fig. 7. It can be seen from the Fig. 7 that there is a strong relationship between the unconfined compressive strength and chloride-ion penetration test results. This plot can be used for a rough estimation of strength or permittivity of LSA-treated sand-bentonite mixtures.

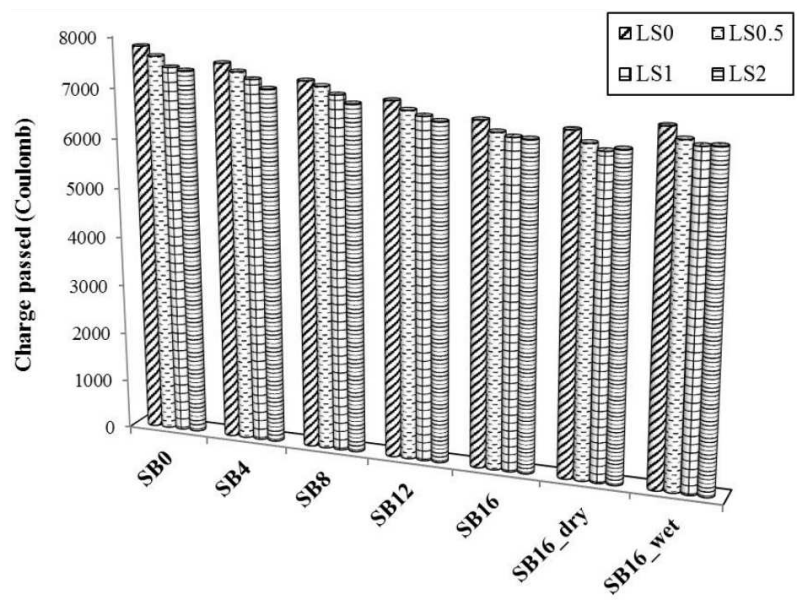

Fig. 6. Variation of chloride-ion penetration of specimens containing LSA.

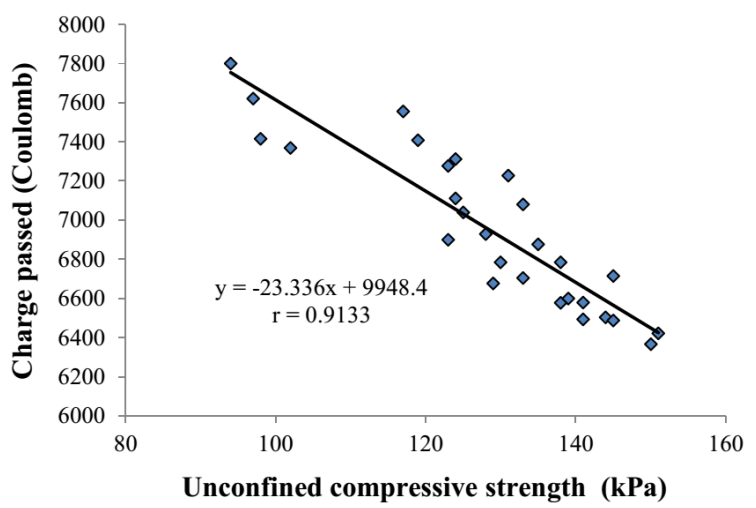

Fig. 7. Relationship between chloride-ion penetration and unconfined compressive strength of specimens.

\section{Conclusions}

Following conclusions can be derived from this study:

- Lignosulfonate is an environmentally friendly additive which can be used for the improvement of sand-bentonite mixtures.

- The addition of lignosulfonate up to $2 \%$ slightly increases the ductility of bentonite. The increase of strength was limited by value of $10 \%$, for the considered mixtures.

- The inclusion of sand somehow increases the strength and improves transport properties of mixtures. A slight increase in strength of sandbentonite mixtures was also provided by substitution of water with $0.5,1$ and $2 \%$ of lignosulfonate.

- Partial replacement of water with lignosulfonate has a considerable effect on strength and permeability, and this effect is more pronounced for the increasing replacement level up to $1 \%$. 
- Effect of lignosulfonate substitution causes a greater strength and lower permeability on the dry side, in comparison with those measured on the wet side.

\section{Acknowledgments}

Support for this study was provided by the Scientific and Technological Research Council of Turkey (TUBITAK) and Ege University Science and Technology Centre - Technology Transfer Office (EBILTEM), under grants number 113M202 and 2014-BIL-009, respectively. Bentonite and sand used in this study were provided by ESAN and Aydınlar Madencilik firms, respectively.

\section{References}

[1] J.F. Chen, S.B. Yu, Int. J. Geomech. 11, 167 (2011).

[2] S.K. Pal, A. Ghosh, Int. J. Geomech. 14, 59 (2014).

[3] P.T. Sherwood, Soil stabilization with cement and lime: state-of the art review, Research Laboratory, Her Majesty's Stationery Office, London 1993.

[4] F. Sariosseiri, B. Muhunthan, Eng. Geol. 104, 119 (2009).
[5] J.S. Vinod, B. Indraratna, in: 13th International Conference of the International Association for Computer Methods and Advances in Geomechanics. Sydney, Australia, Eds. N. Khalili, M. Oeser, Centre for Infrastructure Engineering and Safety, 2011, p. 296.

[6] J.S. Tingle, R.L. Santori, J. Transp. Res. Board 1819, 72 (2003).

[7] B. Indraratna, M. Thevaragavan, M. Khabbaz, R. Armstrong, J. Geotech. Geoenviron. Eng. 134, 837 (2008).

[8] J.W. Adams, Environmental effects of applying lignosulfonate to roads, Research Report, Daishowa Chemicals, (1998) 11 pages.

[9] B. Chen, Brit. Ceram. T. 103, 241 (2004).

[10] A.J. Puppala, S. Hanchanloet, 78th Annual Meeting of the Transportation Research Board, Washington 1999 , p. 23

[11] D. Jones, M. Mitchey, 20th ARRB Conference, 2001, p. 18.

[12] T. Muttuvel, Ph.D. Thesis, University of Wollongong, 2008, p. 216.

[13] J.S. Vinod, B. Indraratna, M.A.A. Mahamud, Proc. ICE-Ground Improvement 163, 43 (2010). 